\title{
Produção, composição do leite e variação do custo e da receita de produção de leite de cabras Saanen recebendo rações com casca de soja em substituição ao milho ${ }^{1}$
}

\section{Milk production and composition, cost and revenue variation of milk production of Saanen goats receiving rations with soybean hulls in replacement to the corn}

\author{
Maximiliane Alavarse Zambom²*; Claudete Regina Alcalde ${ }^{3}$; Elias Nunes Martins ${ }^{3}$; \\ Antonio Ferriani Branco ${ }^{3}$; Karina Toledo Silva ${ }^{4}$; Juliano Hideo Hashimoto \\ Jocilaine Garcia ${ }^{4}$; Paula Adriana Grande ${ }^{4}$
}

\section{Resumo}

O objetivo deste trabalho foi estudar a produção e composição do leite, avaliar as curvas de ingestão de matéria seca, peso vivo e produção de leite ao longo da lactação; além de avaliar a variação do custo e da receita de produção de leite de cabras Saanen, recebendo rações com casca do grão de soja (CGS) em substituição ao milho moído (0\%CGS, 50\%CGS e 100\%CGS). Foram utilizadas 14 cabras $(75,17 \pm$ $9,96 \mathrm{~kg}$ ) distribuídas em delineamento inteiramente casualizado e confinadas em baias individuais. As rações apresentaram em média $14,50 \%$ de $\mathrm{PB}$ e 2,57 Mcal de EM/kg MS ingerida. Os tratamentos não influenciaram $(\mathrm{P}>0,05)$ o peso vivo ( $\mathrm{PV}, \mathrm{kg})$, a ingestão de matéria seca (IMS, $\mathrm{kg} / \mathrm{dia})$ e a produção de leite ao longo do período de lactação. O tratamento com 100\% CGS propiciou um maior teor de gordura no leite $(\mathrm{P}<0,05)$. A casca do grão de soja pode ser utilizada na ração de cabras Saanen em lactação em substituição ao milho moído, pois não altera a IMS, PV e produção de leite, além de propiciar maior teor de gordura no leite e margem sobre o custo da ração.

Palavras-chave: Cabra leiteira, coproduto da agroindústria, custo da ração, desempenho

\begin{abstract}
The objective of this work was to evaluate the milk production and composition, dry matter intake, live weight and milk production curves along lactation, as well as the cost and revenue variation of milk production of Saanen goats fed rations with soybean hulls $(\mathrm{SBH})$ in replacement to the corn $(0 \% \mathrm{SBH}$, $50 \% \mathrm{SBH}$ and $100 \% \mathrm{SBH})$. Fourteen goats were used $(75.17 \pm 9.96 \mathrm{~kg})$ in a completely randomized design and confined in individual pens. The rations presented $14.50 \%$ of $\mathrm{CP}$ and $2.57 \mathrm{Mcal}$ of $\mathrm{ME} / \mathrm{kg}$ DM intake. Treatments did not affect ( $\mathrm{P}>0.05$ ) live weight ( $\mathrm{LW}, \mathrm{kg}$ ), dry matter intake (DMI, $\mathrm{kg} /$ day) and milk production along the lactation period. Soybean hulls can be used as a corn ground replacement in rations for lactating Saanen goats, because it did not change the DMI, LW and milk production. Moreover, it provided greater fat percentage in milk and higher ration cost margin.
\end{abstract}

Key words: Dairy goat, byproduct of agroindustry, ration cost, performance

1 Parte da tese de doutorado do primeiro autor, Projeto financiado pela Fundação Araucária.

2 Prof ${ }^{a}$ da Universidade Estadual do Oeste do Paraná, UNIOESTE, Marechal Cândido Rondon, PR. E-mail:mazambom@hotmail.com

3 Profs.da Universidade Estadual de Maringá, UEM, Maringá, PR.E-mail: cralcalde@wnet.com.br; enmartis@uem.br; afbranco@ uem.br

4 Discente(s) da UEM, Maringá-PR. E-mail: ktols@hotmail.com; jucazoo@hotmail.com; jocilaine@hotmail.com; paulagrde@ hotmail.com

${ }^{*}$ Autor para correspondência 


\section{Introdução}

A caprinocultura nacional é uma atividade com crescimento acentuado e deve-se principalmente à necessidade de se buscar novas alternativas para remunerar os produtores e disponibilizar o leite de cabra e derivados no mercado.

As exigências nutricionais de cabras leiteiras variam significativamente nas diferentes fases do ciclo produtivo, em função do estado fisiológico do animal, alterando a capacidade de ingestão de matéria seca, peso vivo e produção de leite.

A produção e a qualidade do leite de cabra podem variar em função de diversos fatores, tais como, tipo e qualidade da dieta dos animais, raça, período de lactação e clima, além da ação combinada destes fatores nas condições ambientais de cada país ou região (COSTA; QUEIROGA; PEREIRA, 2009).

Costa, Queiroga e Pereira (2009) trabalhando com cabras leiteiras, verificaram que os teores de proteína, gordura e lactose apresentaram variações no decorrer da lactação. Assim, o estudo do comportamento produtivo do animal ao longo da lactação, fornece condições para estabelecer estratégias de manejo nutricional a fim de maximizar a produção e a qualidade do leite.

Para avaliação do comportamento da curva de lactação existem diferentes modelos matemáticos, e o modelo de Wood tem sido usado na maioria dos estudos de curva de lactação, pois permite a estimativa de características básicas da curva, como produção máxima de leite, tempo para se atingir essa produção e persistência, com apenas três parâmetros (WOOD, 1967).

Estudos têm demonstrado a importância da energia no desempenho de cabras em lactação (SCHMIDELY et al., 1999; ZAMBOM et al., 2005). Porém, a maioria dos concentrados utilizados é baseada em grãos de cereais que contêm altos teores de amido. No entanto, resíduos da agroindústria, como a casca do grão de soja (CGS), podem ser utilizados em substituição a estes cereais, fornecendo um alimento com elevado teor de fibra em detergente neutro (acima de 60\%), porém com alta digestibilidade in vitro da parede celular $(95,69 \%$ e $85,65 \%)$ conforme valores observados por Zambom et al. (2001) e Silva et al. (2004), respectivamente.

Zervas et al. (1998) utilizando ovelhas em lactação e Ipharraguerre, Ipharraguerre e Clark (2002) e Hindrichsen et al. (2006) utilizando vacas em lactação, avaliaram a utilização de CGS na dieta e não verificaram diferenças na ingestão de matéria seca e produção de leite. Entretanto, verificaram efeito linear positivo para porcentagem de gordura no leite, em função da inclusão da CGS na ração.

A utilização de resíduos agroindustriais, tal como, a casca do grão de soja, é uma alternativa para minimização dos custos com alimentação. Silva (1998) afirmou que um grande desafio para o caprinocultor brasileiro é a preocupação com seus custos de produção, uma vez que rebanhos estabilizados e em crescimento possuem custos diferenciados. O custo de produção de leite de cabra pode ser alterado por diversos fatores, sendo que as características inerentes aos fatores internos e externos e as estratégias de ação são diferentes.

O aumento da eficiência produtiva é decisivo para competitividade da atividade leiteira, passando pelo gerenciamento do custo de produção (REIS; MEDEIROS; MONTEIRO, 2001). A alimentação dos rebanhos é importante no estabelecimento da rentabilidade, pois é o item de maior impacto nos sistemas de produção de leite (60 a 70\%) (GONÇALVES et. al., 2008).

O objetivo deste trabalho foi estudar a produção e composição do leite, avaliar as curvas de ingestão de matéria seca, peso vivo e produção de leite ao longo da lactação, e avaliar a variação do custo e da receita de produção de leite de cabras Saanen em lactação, recebendo rações com casca do grão de soja em substituição ao milho moído. 


\section{Material e Métodos}

O experimento foi conduzido no Setor de Caprinocultura da Fazenda Experimental de Iguatemi e no Laboratório de Análise de Alimentos e Nutrição Animal, da Universidade Estadual de Maringá, no período de julho de 2004 a fevereiro de 2005.

Foram utilizadas 14 cabras Saanen $(75,17 \pm 9,96$ $\mathrm{kg}$ ), multíparas, durante o período de lactação (do $1^{\circ}$ dia de lactação até a secagem), perfazendo um total de 235 dias de experimento.

As cabras foram distribuídas em delineamento inteiramente casualizado nos tratamentos utilizando rações com diferentes níveis de casca do grão de soja (CGS) em substituição ao milho: 0\%CGS, $50 \%$ CGS e $100 \%$ CGS, com as seguintes repetições: $\mathrm{n}=3, \mathrm{n}=5 \mathrm{n}=6$, respectivamente. $\mathrm{O}$ número de repetições nos tratamentos diferiu devido à morte de alguns animais logo após o parto. Os critérios para alocação dos animais nos tratamentos foram: nível de produção de leite, peso vivo, idade e ordem de parto.

O balanceamento das rações foi feito com base nas exigências em energia e proteína metabolizável (AFRC, 1993), considerando cabra Saanen de $60 \mathrm{~kg}$ de peso vivo e produção de $3,0 \mathrm{~kg}$ de leite por dia (Tabela 1).

Tabela 1. Composições percentual e química das rações (\%MS).

\begin{tabular}{lrrc}
\hline \multirow{2}{*}{ Alimentos } & \multicolumn{3}{c}{ Dietas $^{1}$} \\
\cline { 2 - 4 } & $0 \%$ CGS & $50 \%$ CGS & $100 \%$ CGS \\
\hline Silagem de milho & 40,00 & 40,00 & 16,00 \\
Farelo de soja & 17,29 & 18,27 & - \\
Milho moído & 40,19 & 20,18 & 41,32 \\
Casca do grão de soja & - & 19,46 & 1,22 \\
Sal comum & 1,21 & 1,21 & - \\
Calcário calcítico & 0,63 & 0,25 & 0,16 \\
Fosfato bicálcico & 0,19 & 0,14 & 0,50 \\
Suplemento mineral ${ }^{2}$ & 0,50 & 0,50 & 66,48 \\
\hline Matéria Seca (\%) & 65,15 & 65,78 & 92,89 \\
Matéria orgânica (\%MS) & 94,46 & 93,78 & 15,85 \\
Proteína Bruta (\%MS) & 13,57 & 15,11 & 47,11 \\
FDN (\%MS) & 28,98 & 37,51 & 32,44 \\
FDA (\%MS) & 16,10 & 23,85 & 5,40 \\
Lignina (\%MS) & 3,29 & 4,29 & 0,38 \\
Cálcio (\%MS) & 0,41 & 0,36 & 0,23 \\
Fósforo (\%MS) & 0,26 & 0,24 & 58,66 \\
NDT (\%) & 66,60 & 62,95 & 2,59 \\
EM (Mcal/kg de MS) & 2,94 & 2,78 & \\
\hline
\end{tabular}

${ }^{1} 0 \%$ CGS-0 $\%$ de casca do grão de soja em substituição ao milho moído, $50 \%$ CGS-50\% de casca do grão de soja em substituição ao milho moído, $100 \%$ CGS-100\% de casca do grão de soja em substituição ao milho moído.

${ }^{2}$ Composição Química (por kg do produto): 80,00 g Ca, 65,00 g P, 126,00 mg Co, 21,00 mg Mg, 4400,00 mg Mn, 185,00 mg Na, 4680,00 mg Zn, 45,00 mg Se, 60,00 mg I, 23,00 g S, 615,79 mg F (max.), 7000,00 mg niacina (produto comercial).

${ }^{3}$ Estimado pela fórmula de Sniffen et al. (1992): $\mathrm{CT}=100-(\% \mathrm{~PB}+\% \mathrm{EE}+\%$ Cinzas $)$

Fonte: Elaboração dos autores. 
As cabras foram mantidas em baias individuais, contendo bebedouro e comedouro. $\mathrm{O}$ fornecimento das rações foi realizado duas vezes ao dia, às 10:00 e 16:00h. Foram realizadas duas ordenhas ao dia (7:30 e 15:00 h), sendo que, logo após a ordenha da manhã os animais eram conduzidos ao solário, permanecendo por aproximadamente duas horas.

A pesagem das rações fornecidas (silagem de milho e concentrado) e das sobras foi realizada diariamente. No início do experimento e a cada 15 dias foram realizadas as pesagens dos animais, logo após a ordenha e antes da alimentação da manhã.

Durante o período de lactação, houve o controle diário de produção de leite. Para análise da composição e qualidade do leite, foram coletadas amostras (8:00 e 15:00h) mensalmente, a partir de quinze dias de lactação, sendo estas acondicionadas em frasco plástico contendo conservante Bronopol (2-bromo-2-nitro-1,3-propanodiol). As amostras foram analisadas pelo método do analisador infravermelho Bentley $2000^{\circledR}$, para os teores de sólidos totais, de proteína bruta, de gordura e de lactose. A contagem de células somáticas foi realizada por um contador eletrônico Somacount $500^{\circledR}$. Todas as análises foram feitas no Laboratório do Programa de Análises do Rebanho Leiteiro do Paraná (PARLPR) da Associação Paranaense de Criadores de Bovinos da Raça Holandesa, sendo que os equipamentos foram calibrados para análise de leite de vaca.

A produção de leite corrigida para 3,5\% de gordura foi estabelecida segundo a fórmula de Gravert (1987):

$$
\operatorname{LCG}(3,5 \%)=0,4337 \mathrm{PL}+16,218 \mathrm{PG}
$$

Onde,

LCG: leite corrigido para gordura;

PL: produção de leite $(\mathrm{kg} / \mathrm{dia})$;

PG: produção de gordura (kg/dia).

Os alimentos utilizados na formulação das rações para as cabras durante o experimento foram adquiridos de empresas da região de Maringá - PR. Os preços unitários dos alimentos e da ração total à época do experimento encontram-se nas Tabelas 2 e 3, respectivamente. Segundo Cordeiro (2005) no Brasil o preço do litro de leite pago ao produtor fica em torno de US\$ 0,39 a 0,43 . O valor utilizado no trabalho, para os cálculos de receita com a venda do leite foi de US\$ 0,41. Portanto, em função da variação cambial durante os meses estudados o preço por litro de leite pago ao produtor foi de R\$ 1,07 à $\mathrm{R} \$ 1,25$. O preço médio das rações foi de $\mathrm{R} \$$ $0,33 / \mathrm{kg}, \mathrm{R} \$ 0,32 / \mathrm{kg}$ e R $\$ 0,29 / \mathrm{kg}$, respectivamente aos tratamentos 0\%CGS, 50\%CGS e 100\%CGS.

No trabalho, não foram considerados os custos da mão-de-obra utilizada, nem os juros sobre o capital de giro. Optou-se por avaliar a eficiência produtiva de cabras leiteiras recebendo casca do grão de soja em substituição ao milho moído na ração, por meio da análise econômica denominada orçamentação parcial, segundo metodologia descrita por Hoffmann et al. (1992), onde se avaliaram os custos, as receitas e o retorno médio da margem sobre o custo da ração. 
Tabela 2. Preços $(\mathrm{R} \$ / \mathrm{kg})$ dos alimentos utilizados na formulação das rações nos meses de Julho de 2004 a Fevereiro de 2005.

\begin{tabular}{lrrrrrrrr}
\hline \multicolumn{1}{c}{ Preços } & \multicolumn{3}{c}{2004} & & & \multicolumn{3}{c}{2005} \\
\hline \multicolumn{1}{c}{ R $\mathbf{k g}$ MN } & Jul & Ago & Set & Out & Nov & Dez & Jan & Fev \\
\hline Silagem milho & 0,04 & 0,04 & 0,04 & 0,04 & 0,04 & 0,03 & 0,03 & 0,04 \\
Farelo de soja & 0,55 & 0,60 & 0,57 & 0,52 & 0,49 & 0,51 & 0,51 & 0,50 \\
Milho moído & 0,26 & 0,24 & 0,25 & 0,23 & 0,21 & 0,20 & 0,21 & 0,21 \\
Casca de soja & 0,18 & 0,18 & 0,18 & 0,18 & 0,18 & 0,18 & 0,18 & 0,18 \\
Sal comum & 0,33 & 0,33 & 0,33 & 0,34 & 0,34 & 0,34 & 0,34 & 0,34 \\
Calcário & 0,16 & 0,16 & 0,15 & 0,15 & 0,15 & 0,15 & 0,15 & 0,15 \\
Fosfato Bicálcico & 1,32 & 1,32 & 1,32 & 1,32 & 1,32 & 1,32 & 1,32 & 1,32 \\
Suplemento mineral & 1,16 & 1,16 & 1,16 & 1,16 & 1,16 & 1,16 & 1,16 & 1,16 \\
\hline US\$ & 3,05 & 3,01 & 2,91 & 2,85 & 2,80 & 2,72 & 2,70 & 2,60 \\
\hline
\end{tabular}

${ }^{1}$ Equivalente de 1 US\$ em R\$

Fonte: Elaboração dos autores.

Tabela 3. Preços das rações $(\mathrm{R} \$ / \mathrm{kg})$, por tratamento nos meses de Julho de 2004 a Fevereiro de 2005.

\begin{tabular}{lccc}
\hline \multirow{2}{*}{ Mês/ano } & \multicolumn{3}{c}{ Dietas (R $/ \mathrm{kg} \mathrm{MN})^{1}$} \\
\cline { 2 - 4 } & $0 \%$ CGS & $50 \%$ CGS & $100 \%$ CGS \\
\hline Julho de 2004 & 0,36 & 0,33 & 0,30 \\
Agosto de 2004 & 0,36 & 0,34 & 0,31 \\
Setembro de 2004 & 0,35 & 0,33 & 0,30 \\
Outubro de 2004 & 0,33 & 0,31 & 0,29 \\
Novembro de 2004 & 0,31 & 0,30 & 0,28 \\
Dezembro de 2004 & 0,30 & 0,30 & 0,29 \\
Janeiro de 2005 & 0,31 & 0,30 & 0,29 \\
Fevereiro de 2005 & 0,31 & 0,30 & 0,28 \\
Média & 0,33 & 0,32 & 0,29 \\
\hline
\end{tabular}

${ }^{1} 0 \%$ CGS-0\% de casca do grão de soja em substituição ao milho moído, 50\%CGS-50\% de casca do grão de soja em substituição ao milho moído, $100 \%$ CGS-100\% de casca do grão de soja em substituição ao milho moído.

Fonte: Elaboração dos autores.

Os dados foram analisados por meio da análise de variância e o teste de média utilizado foi o Tukey a 5\% de probabilidade. O modelo estatístico utilizado foi:

$$
Y i j=\mu+T i+e i j
$$

Onde:

Yij: observação do animal j recebendo o tratamento

$\mathrm{i}, \mathrm{i}=0,50$ e 100 ;

$\mu$ : constante geral;

Ti: efeito do tratamento $i, i=0,50$ e 100 ;

eij: erro aleatório associado a cada observação.

\section{Resultados e Discussão}

A ingestão de matéria seca, dias de lactação e produção de leite durante o período de lactação, não diferiu $(\mathrm{P}>0,05)$ entre as dietas com diferentes teores de casca de grão de soja (Tabela 4). 
Tabela 4. Valores médios e erros padrão de ingestão de matéria seca (IMS, kg/dia), dias de lactação, produção de leite (PL, kg/dia) e produção de leite total (PLT,kg) de cabras Saanen recebendo rações com casca do grão de soja (CGS) em substituição ao milho moído.

\begin{tabular}{lcccrr}
\hline \multirow{2}{*}{ Variáveis } & \multicolumn{3}{c}{ Dietas $^{1}$} & \multicolumn{1}{c}{ CV } \\
\cline { 2 - 5 } & $0 \% \operatorname{CGS}(n=3)$ & $50 \% \operatorname{CGS~}(n=5)$ & $100 \% \operatorname{CGS~}(n=6)$ & Média & \multicolumn{1}{c}{$\%$} \\
\hline IMS (kg/dia) & $2,33 \pm 0,21$ & $2,06 \pm 0,16$ & $2,26 \pm 0,15$ & $2,22 \pm 0,10$ & 16,3 \\
Dias de lactação & $271,67 \pm 10,25$ & $282,80 \pm 7,94$ & $293,17 \pm 7,25$ & $282,54 \pm 4,95$ & 6,3 \\
PL (kg/dia) & $3,24 \pm 0,70$ & $2,66 \pm 0,55$ & $3,11 \pm 0,50$ & $3,00 \pm 0,34$ & 40,9 \\
PLG (kg/dia) & $2,99 \pm 0,65$ & $2,56 \pm 0,50$ & $3,14 \pm 0,46$ & $2,89 \pm 0,31$ & 38,7 \\
PLT (kg) & $867,51 \pm 208,14$ & $753,55 \pm 161,23$ & $917,44 \pm 147,18$ & $848,21 \pm 100,54$ & 42,5 \\
\hline
\end{tabular}

${ }^{1} 0 \%$ CGS-0\% de casca do grão de soja em substituição ao milho moído, $50 \%$ CGS-50\% de casca do grão de soja em substituição ao milho moído, $100 \%$ CGS-100\% de casca do grão de soja em substituição ao milho moído.

Fonte: Elaboração dos autores.

A dieta com 100\% CGS proporcionou maior teor de gordura no leite (Tabela 5), o que provavelmente é resultado do maior teor de fibra em detergente neutro da ração, que por sua vez promove um acréscimo de acetato ruminal (ZAMBOM et al., 2007). Fato este corroborado por Zervas et al. (1998) utilizando ovelhas em lactação e Ipharraguerre, Ipharraguerre e Clark (2002) e Hindrichsen et al. (2006) utilizando vacas em lactação, os quais avaliaram a utilização de CGS na dieta e não verificaram diferenças na ingestão de matéria seca e produção de leite. Entretanto, verificaram efeito linear positivo para porcentagem de gordura no leite, em função da inclusão de CGS na ração.

Tabela 5. Médias, erros padrões e coeficientes de variação para percentagem de gordura, proteína, lactose, sólidos totais e contagem de células somáticas (CCS, cel/mL, x1000), no leite de cabras Saanen recebendo rações com casca do grão de soja (CGS) em substituição ao milho.

\begin{tabular}{lcccrr}
\hline & \multicolumn{3}{c}{ Dietas $^{1}$} & CV \\
\cline { 1 - 4 } & 0\%CGS $(n=3)$ & $50 \%$ CGS $(n=5)$ & $100 \%$ CGS $(n=6)$ & Média & \\
\hline Gordura (\%) & $3,07 \pm 0,10 \mathrm{~b}$ & $2,26 \pm 0,07 \mathrm{~b}$ & $3,59 \pm 0,06 \mathrm{a}$ & $3,31 \pm 0,05$ & 14,1 \\
Proteína (\%) & $2,84 \pm 0,05$ & $2,93 \pm 0,04$ & $2,82 \pm 0,03$ & $2,87 \pm 0,02$ & 8,2 \\
Lactose (\%) & $4,33 \pm 0,06 \mathrm{a}$ & $4,15 \pm 0,05 \mathrm{~b}$ & $4,16 \pm 0,04 \mathrm{ab}$ & $4,22 \pm 0,03$ & 7,2 \\
Sólidos Totais (\%) & $11,14 \pm 0,17$ & $11,19 \pm 0,13$ & $11,43 \pm 0,12$ & $11,27 \pm 0,08$ & 7,6 \\
CCS (cel/mLx1000) & $1165 \pm 285 \mathrm{~b}$ & $2056 \pm 209 \mathrm{a}$ & $1158 \pm 191 \mathrm{~b}$ & $1447 \pm 134$ & 94,5 \\
\hline
\end{tabular}

${ }^{1} 0 \%$ CGS- $0 \%$ de casca do grão de soja em substituição ao milho moído, $50 \%$ CGS- $50 \%$ de casca do grão de soja em substituição ao milho moído, 100\%CGS-100\% de casca do grão de soja em substituição ao milho moído.

Médias seguidas por letras diferentes na mesma linha diferem pelo teste de Tukey a 5\% de probabilidade.

Fonte: Elaboração dos autores.

O menor teor de lactose obtido no tratamento $50 \%$ CGS provavelmente deve-se à maior contagem de células somáticas, que por sua vez está relacionada a uma à maior incidência de mastite. Segundo Haenlein (2004) a presença de mastite na glândula mamária de fêmeas em lactação altera a composição do leite, elevando os teores de proteínas do soro, lipase, sódio e cloreto e diminuindo os níveis de gordura, sólidos totais, caseína, lactose, cálcio, fósforo e potássio.

A variação de peso vivo $(\mathrm{kg})$ ao longo do ciclo produtivo não foi influenciada $(\mathrm{P}>0,05)$ pelas dietas. No entanto, houve variações de peso devido à fase produtiva em que o animal se encontrava (Figura 1). 
Figura 1. Peso vivo (kg) de cabras Saanen ao longo do ciclo produtivo recebendo casca do grão de soja em substituição ao milho moído.

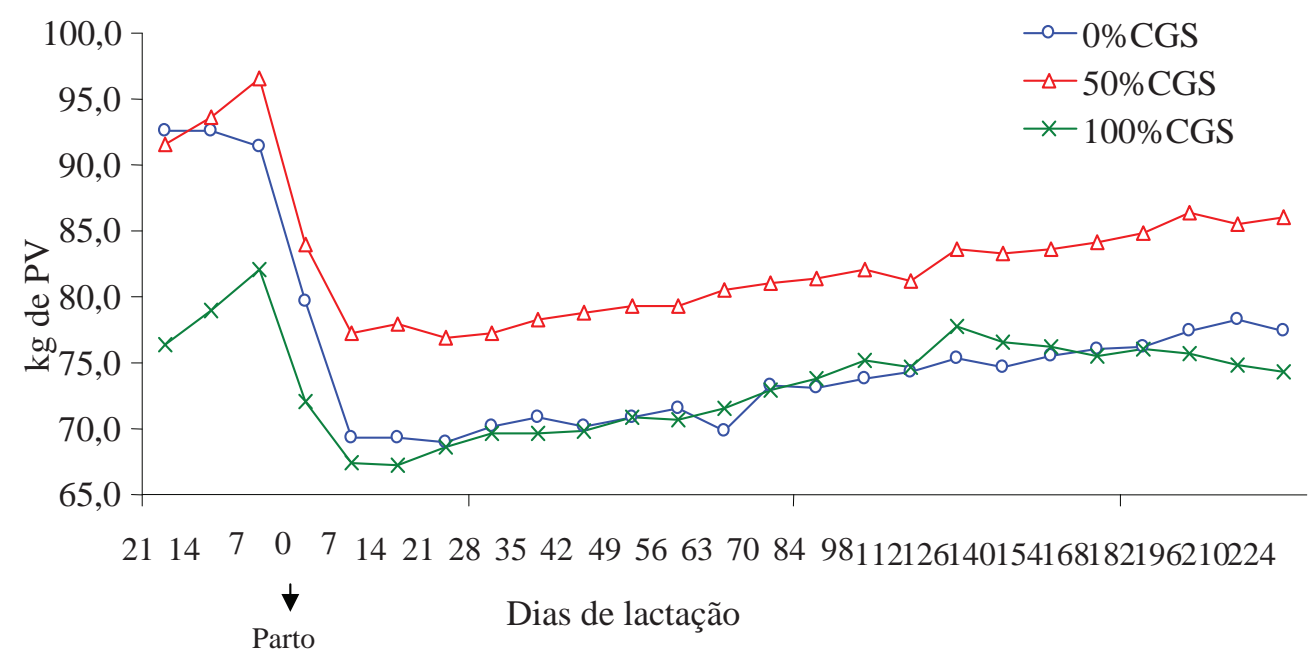

Fonte: Elaboração dos autores.

As perdas decorrentes do parto e o início da lactação acarretam em redução no escore corporal e no peso dos animais. A diminuição de peso vivo ocorre até aproximadamente quatro a cinco semanas de lactação, pois neste período a cabra está em balanço energético negativo, isto é, o animal não consegue ingerir a quantidade de nutrientes necessários para produção de leite e sua manutenção.

A utilização da casca do grão de soja em substituição ao milho moído na ração de cabras Saanen, não alterou a ingestão de matéria seca ( $\mathrm{P}>0,05)$ ao longo do ciclo produtivo (Figura 2 ).

Figura 2. Ingestão de matéria seca $(\mathrm{kg} / \mathrm{dia})$ de cabras Saanen ao longo do ciclo produtivo recebendo casca do grão de soja em substituição ao milho moído.

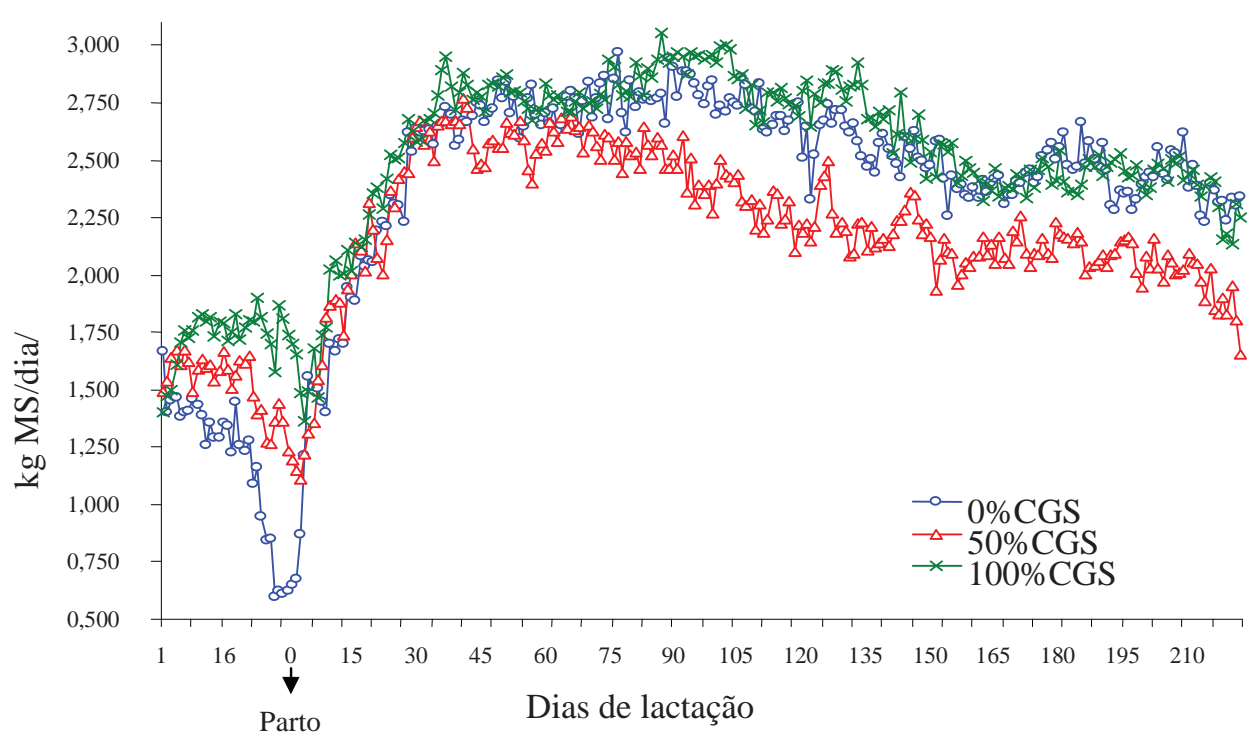

Fonte: Elaboração dos autores. 
Durante o período pré-parto a ingestão de matéria seca (IMS) pelo animal é reduzida, devido à compressão do rúmen pelo útero grávido, no entanto, a utilização da casca de soja na ração diminuiu esta redução na ingestão, provavelmente devido à alta digestibilidade in vitro da parede celular, segundo Zambom et al. (2001) e Silva et al. (2004) (95,69\% e $85,65 \%$, respectivamente).

Após o parto a IMS aumentou gradativamente, tendo a máxima ingestão ocorrida entre $45^{\circ}$ e $90^{\circ}$ dias de lactação, coincidindo com o pico de lactação das cabras, o qual ocorreu aos $48^{\circ}$ dias de lactação. Nesta fase, logo após o pico de lactação, as cabras estavam em balanço energético positivo, pois a ingestão de matéria seca estava maximizada.

As curvas de produção de leite na lactação de cabras Saanen, recebendo casca do grão de soja em substituição ao milho moído da ração, estão apresentadas na Figura 3.

Figura 3. Produção de leite $(\mathrm{kg} / \mathrm{dia})$ de cabras Saanen recebendo casca do grão de soja em substituição ao milho moído.

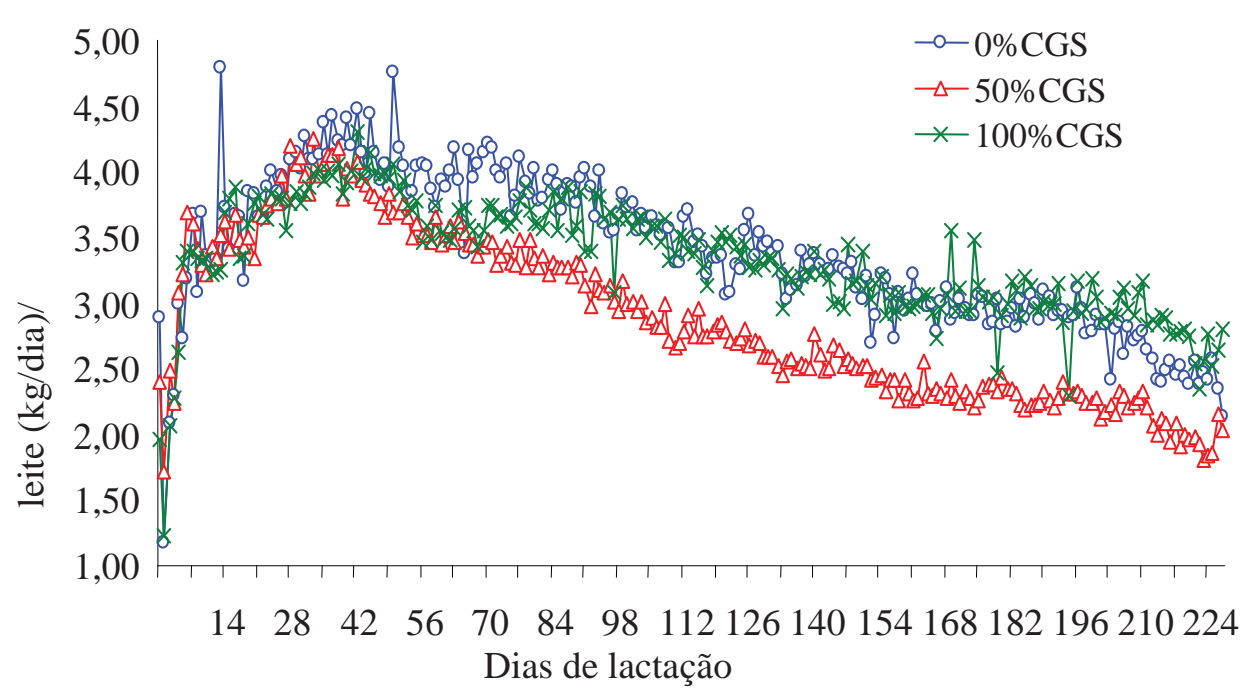

Fonte: Elaboração dos autores.

Ao longo do período de lactação não foram verificadas diferenças ( $\mathrm{P}>0,05$; Figura 3 ) entre os diferentes teores de inclusão de casca de grão de soja, para ingestão de matéria seca e produção de leite. Assim, os fatores preponderantes na escolha da dieta a ser utilizada são os custos com a alimentação e a receita com a venda do leite, determinando-se a margem sobre o custo da ração.

O conhecimento do custo de produção do leite e de seus componentes é primordial para o sucesso da produção, pois auxilia o produtor de leite na tomada de decisões. O produtor deve buscar a especificação na produção de leite, melhorando o aproveitamento dos fatores de produção, com aumento da produtividade e do volume de produção (BORGES; BRESSLAU, 2002).

Durante os meses de Julho de 2004 a Fevereiro de 2005, houve diferenças na ingestão média de ração, em função do estádio de lactação dos animais. Assim, os dados referentes a ingestão de matéria natural pelas cabras no referido período podem ser visualizados na Tabela 6 , tal como, os custos com a alimentação (Tabela 7), já que houve uma variação com o custo das rações (Tabela 2) no período avaliado. 
Tabela 6. Ingestão média de ração (IMN-kg de matéria natural/cabra/dia) por cabras Saanen recebendo rações com casca do grão de soja (CGS) em substituição ao milho moído nos meses de Julho de 2004 a Fevereiro de 2005.

\begin{tabular}{lccc}
\hline \multirow{2}{*}{ IMN/cabra/dia } & \multicolumn{3}{c}{ Dietas $^{1}$} \\
\cline { 2 - 4 } & 0\%CGS & $50 \%$ CGS & $100 \%$ CGS \\
\hline Julho de 2004 & 2,74 & 3,34 & 3,69 \\
Agosto de 2004 & 4,78 & 4,72 & 5,31 \\
Setembro de 2004 & 4,06 & 5,13 & 5,38 \\
Outubro de 2004 & 5,05 & 4,88 & 5,65 \\
Novembro de 2004 & 5,17 & 4,52 & 5,38 \\
Dezembro de 2004 & 5,07 & 4,29 & 4,86 \\
Janeiro de 2005 & 5,13 & 4,19 & 4,82 \\
Fevereiro de 2005 & 4,92 & 3,87 & 4,46 \\
\hline Média & 4,61 & 4,37 & 4,94 \\
\hline
\end{tabular}

${ }^{1} 0 \%$ CGS-0\% de casca do grão de soja em substituição ao milho moído, $50 \%$ CGS-50\% de casca do grão de soja em substituição ao milho moído, $100 \%$ CGS-100\% de casca do grão de soja em substituição ao milho moído.

Fonte: Elaboração dos autores.

Tabela 7. Despesas médias diárias (R $\$$ cabra/dia) com a ingestão de ração (IMN-kg de matéria natural) por cabras Saanen recebendo rações com casca do grão de soja (CGS) em substituição ao milho moído, nos meses de Julho de 2004 a Fevereiro de 2005.

\begin{tabular}{lccc}
\hline \multicolumn{1}{c}{ Mês/ano } & \multicolumn{3}{c}{ Dietas (R\$/MN/cabra/dia) $)^{1}$} \\
\cline { 2 - 4 } & $0 \%$ CGS & $50 \%$ CGS & $100 \%$ CGS \\
\hline Julho de 2004 & 0,63 & 0,73 & 1,08 \\
Agosto de 2004 & 1,10 & 1,05 & 1,06 \\
Setembro de 2004 & 0,92 & 1,11 & 1,07 \\
Outubro de 2004 & 1,06 & 0,99 & 0,98 \\
Novembro de 2004 & 1,03 & 0,88 & 0,90 \\
Dezembro de 2004 & 0,98 & 0,83 & 0,89 \\
Janeiro de 2005 & 1,02 & 0,82 & 0,82 \\
Fevereiro de 2005 & 0,98 & 0,76 & 0,94 \\
\hline Média & 0,97 & 0,90 & \\
\hline
\end{tabular}

${ }^{1} 0 \%$ CGS-0\% de casca do grão de soja em substituição ao milho moído, $50 \%$ CGS-50\% de casca do grão de soja em substituição ao milho moído, $100 \%$ CGS-100\% de casca do grão de soja em substituição ao milho moído.

Fonte: Elaboração dos autores.

A produção de leite de cabras Saanen varia no decorrer do estádio de lactação, havendo um acréscimo na produção de leite até o pico de lactação e decréscimo na produção diária após o mesmo. Assim, no decorrer do período de lactação há diferença quanto a produção de leite (Tabela 8).

A variação cambial do dólar faz com que haja alterações quanto ao valor médio pago ao produtor por $\mathrm{kg}$ de leite produzido. Sendo que, no decorrer do período de lactação o valor do preço do $\mathrm{kg}$ de leite pago ao produtor foi de: $\mathrm{R} \$ 1,25 ; \mathrm{R} \$ 1,23 ; \mathrm{R} \$$ 1,$19 ; \mathrm{R} \$ 1,17 ; \mathrm{R} \$ 1,15 ; \mathrm{R} \$ 1,12 ; \mathrm{R} \$ 1,11$ e $\mathrm{R} \$ 1,07$; respectivamente aos meses avaliados (julho de 2004 a fevereiro de 2005).

Em função das diferenças quanto à produção de leite e valor do leite pago ao produtor, há variações quanto a receita com a venda do leite no decorrer do período de lactação avaliado (Tabela 9), também, pode-se notar diferenças entre as dietas com diferentes teores de casca de grão de soja, sendo estas variáveis de acordo com o mês avaliado. 
Tabela 8. Produção média de leite ( $\mathrm{kg} / \mathrm{cabra} / \mathrm{dia})$ de cabras Saanen recebendo rações com casca do grão de soja (CGS) em substituição ao milho moído nos meses de Julho de 2004 a Fevereiro de 2005.

\begin{tabular}{lccc}
\hline \multirow{2}{*}{ Mês/ano } & \multicolumn{3}{c}{ Dietas (leite/cabra/dia) ${ }^{1}$} \\
\cline { 2 - 4 } & $0 \%$ CGS & $50 \%$ CGS & $100 \%$ CGS \\
\hline Julho de 2004 & 3,00 & 3,46 & 2,95 \\
Agosto de de 2004 & 3,50 & 3,70 & 3,84 \\
Setembro de 2004 & 3,09 & 3,58 & 3,71 \\
Outubro de 2004 & 3,80 & 3,16 & 3,61 \\
Novembro de 2004 & 3,74 & 2,78 & 3,37 \\
Dezembro de 2004 & 3,50 & 2,48 & 3,10 \\
Janeiro de 2005 & 3,25 & 2,31 & 3,02 \\
Fevereiro de 2005 & 3,08 & 2,16 & 2,83 \\
\hline Média & 3,37 & 2,95 & 3,30 \\
\hline
\end{tabular}

${ }^{1} 0 \%$ CGS-0\% de casca do grão de soja em substituição ao milho moído, $50 \%$ CGS- $50 \%$ de casca do grão de soja em substituição ao milho moído, 100\%CGS-100\% de casca do grão de soja em substituição ao milho moído.

Fonte: Elaboração dos autores.

Tabela 9. Receitas médias diárias (R \$/cabra/dia) com a produção de leite de cabras Saanen recebendo rações com casca do grão de soja (CGS) em substituição ao milho moído nos meses de Julho de 2004 a Fevereiro de 2005.

\begin{tabular}{lccc}
\hline \multirow{2}{*}{ Mês/ano } & \multicolumn{3}{c}{ Dietas (R $\$ /$ cabra/dia) ${ }^{1}$} \\
\cline { 2 - 4 } & $0 \%$ CGS & $50 \%$ CGS & $100 \%$ CGS \\
\hline Julho de 2004 & 3,75 & 4,32 & 3,68 \\
Agosto & 4,32 & 4,56 & 4,74 \\
Setembro & 3,69 & 4,27 & 4,42 \\
Outubro & 4,44 & 3,69 & 4,22 \\
Novembro & 4,29 & 3,20 & 3,87 \\
Dezembro & 3,91 & 2,76 & 3,45 \\
Janeiro de 2005 & 3,60 & 2,55 & 3,34 \\
Fevereiro de 2005 & 3,28 & 2,30 & 3,02 \\
\hline Média & 3,91 & 3,46 & 3,84 \\
\hline
\end{tabular}

${ }^{1} 0 \%$ CGS- $0 \%$ de casca do grão de soja em substituição ao milho moído, $50 \%$ CGS- $50 \%$ de casca do grão de soja em substituição ao milho moído, $100 \%$ CGS-100\% de casca do grão de soja em substituição ao milho moído.

Fonte: Elaboração dos autores.

Os valores médios obtidos para despesas com alimentação variaram de $\mathrm{R} \$ 0,90$ a $\mathrm{R} \$ 0,97$, por animal por dia. Para a receita com a venda do leite, a variação foi de $\mathrm{R} \$ 3,46$ a $\mathrm{R} \$ 3,91$, sendo estes resultados semelhantes aos obtidos por Alcalde et al. (2005), que avaliaram a utilização de diferentes relações de volumoso:concentrado para cabras Saanen em lactação, durante os meses de Julho a Dezembro de 2002. O preço por kg de ração variou de $\mathrm{R} \$ 0,36$ a $\mathrm{R} \$ 0,45$, utilizando como fonte de volumoso o feno de aveia. A despesa diária com o consumo de ração variou de $\mathrm{R} \$ 0,69$ a $\mathrm{R} \$ 1,20$, e a receita diária com a venda do leite, considerando o valor de $\mathrm{R} \$ 0,90 / \mathrm{kg}$ de leite, variou de $\mathrm{R} \$ 1,65 \mathrm{a}$ $\mathrm{R} \$ 2,98$.

A margem sobre o custo da ração (MCR), obtida por meio da redução da receita com a venda do leite e os custos com a alimentação, durante o período de lactação avaliado, é apresentada na Tabela 10. 
Tabela 10. Margem sobre o custo da ração (MCR) (R \$dia), de cabras Saanen recebendo rações com casca do grão de soja (CGS) em substituição ao milho moído nos meses de Julho de 2004 a Fevereiro de 2005.

\begin{tabular}{llcl}
\hline \multirow{2}{*}{ Mês/ano } & \multicolumn{3}{c}{${\text { Dietas }(\mathrm{R} \$ / \mathrm{dia})^{1}}^{\mathbf{1}}$} \\
\cline { 2 - 4 } & $0 \% \mathrm{CGS}$ & $50 \% \mathrm{CGS}$ & $100 \% \mathrm{CGS}$ \\
\hline Julho de 2004 & 3,11 & 3,59 & 2,96 \\
Agosto de 2004 & 3,22 & 3,51 & 3,66 \\
Setembro de 2004 & 2,76 & 3,16 & 3,36 \\
Outubro de 2004 & 3,38 & 2,70 & 3,15 \\
Novembro de 2004 & 3,27 & 2,32 & 2,88 \\
Dezembro de 2004 & 2,92 & 1,93 & 2,56 \\
Janeiro de 2005 & 2,58 & 1,73 & 2,45 \\
Fevereiro de 2005 & 2,29 & 1,54 & 2,19 \\
Média & 2,94 & 2,56 & 2,90 \\
\hline
\end{tabular}

${ }^{1} 0 \%$ CGS-0\% de casca do grão de soja em substituição ao milho moído, 50\%CGS-50\% de casca do grão de soja em substituição ao milho moído, $100 \%$ CGS-100\% de casca do grão de soja em substituição ao milho moído.

Fonte: Elaboração dos autores.

Em função das variações mensais quanto ao preço/ kg de ração e preço pago ao produtor por $\mathrm{kg}$ de leite, observou-se diferenças entre as dietas com diferentes teores de casca de grão de soja e entre os meses estudados. Sendo que a média da MCR obtida no presente estudo (Tabela 10) foi superior à obtida por Alcalde et al. (2005), esta disparidade deve-se às diferenças quanto o tipo de alimento utilizado, principalmente o volumoso, variações quanto ao valor pago ao produtor pelo $\mathrm{kg}$ de leite produzido e distinções quanto a produção de leite dos animais.

Atualmente algumas empresas remuneram o leite pela sua qualidade, sendo assim, há um acréscimo no valor pago ao produtor pelo teor de gordura do leite. Portanto, quanto maior o teor de gordura do leite, maior o valor pago por este.
Como não foram observadas diferenças entre os tratamentos $(\mathrm{P}>0,05)$ para ingestão de matéria seca e produção de leite; foi realizada uma análise de receita com a venda do leite, custo com a ração e margem sobre o custo da ração, utilizando-se um valor médio de ingestão de ração $(4,64 \mathrm{~kg}$ de $\mathrm{MN} /$ dia) e produção de leite $(3,21 \mathrm{~kg} /$ dia $)$, e verificaramse as seguintes MCR: 2,74; 2,77 e 2,84 para os tratamentos $0 \% \mathrm{CGS}, \quad 50 \% \mathrm{CGS}$ e $100 \% \mathrm{CGS}$, respectivamente (Tabela 11). Pode-se notar que a utilização de $100 \%$ de casca do grão de soja, quando comparada a ração com $0 \% \mathrm{CGS}$, proporciona um acréscimo de 3,6\% na MCR, ou R\$ 0,10/cabra/dia. Considerando uma propriedade com as mesmas características avaliadas, com 30 cabras em lactação, durante um mês a MCR seria de R\$90,00. 
Tabela 11. Valores médios, em $\mathrm{R} \$$ dia, da receita com a venda do leite, custo da ração e margem sobre o custo da ração (MCR) de cabras Saanen recebendo rações com casca do grão de soja (CGS) em substituição ao milho moído.

\begin{tabular}{lccc}
\hline & \multicolumn{3}{c}{$\operatorname{Dietas}^{I}$} \\
\cline { 2 - 4 } & $0 \%$ CGS $(n=3)$ & $50 \%$ CGS $(n=5)$ & $100 \%$ CGS $(n=6)$ \\
\hline Receita com a venda do leite/dia & 3,91 & 3,46 & 3,84 \\
Custo da ração/dia & 0,97 & 0,90 & 0,94 \\
MCR $^{2}$ & 2,94 & 2,56 & 2,90 \\
\hline
\end{tabular}

${ }^{1} 0 \%$ CGS-0\% de casca do grão de soja em substituição ao milho moído, $50 \%$ CGS- $50 \%$ de casca do grão de soja em substituição ao milho moído, 100\%CGS-100\% de casca do grão de soja em substituição ao milho moído.

${ }^{2}$ Margem sobre o custo da ração

Fonte: Elaboração dos autores.

\section{Conclusões}

Nas condições deste experimento, a casca do grão de soja pode ser utilizada em substituição ao milho moído em rações para cabras em lactação, pois não altera a ingestão de matéria seca e produção de leite, e ainda, proporciona um maior teor de gordura no leite, podendo assim, proporcionar maior margem sobre o custo da ração.

\section{Agradecimentos}

A Fundação Araucária pelo financiamento do projeto de pesquisa, ao $\mathrm{CNPq}$ pela concessão de bolsa de pesquisa e a COCAMAR pelo fornecimento da casca do grão de soja necessária para realização do experimento.

\section{Referências}

AGRICULTURALAND FOOD RESEARCHCOUNCIL - AFRC. Energy and Protein requirements of ruminant. Ed. CAB Internacional, Wallingford, UK, 1993. 159 p.

ALCALDE, C. R.; ZAMBOM, M. A.; BORGHI, E. L.; MACEDO, F. A. F.; PEREIRA, M. F.; GARCIA, J. Variação do custo e da receita de produção de leite de cabras saanen, recebendo rações com diferentes relações de volumoso:concentrado. Acta Scientiarum. Animal Sciences, Maringá, v. 27, n. 4, p. 547-553, 2005.

BORGES, C. H. P.; BRESSLAU, S. Produção de leite de cabra em confinamento. In: SIMPÓSIO DE PECUÁRIA DO NORDESTE-PECNORDESTE, 6.; SEMANA DACAPRINO-OVINOCULTURA BRASILEIRA, 3., 2002, Fortaleza. Anais... Fortaleza: [s.n], 2002. p. 12-24.
CORDEIRO, P. R. C. O mercado do leite de cabra e seus derivados. In: SIMPÓSIO PAULISTA DE CAPRINOCULTURA, 1., 2005, Jaboticabal. Anais... Jaboticabal: Faculdade de Ciências Agrárias e Veterinárias, UNESP, 2005. p. 112-118.

COSTA, R. G.; QUEIROGA, R. C. R. E.; PEREIRA, R. A. G. Influência do alimento na produção e qualidade do leite de cabra. Revista Brasileira de Zootecnia, Viçosa, v. 38, p. 307-321, 2009. Suplemento especial.

GONÇALVES, A. L.; LANA, R. de P.; VIEIRA, R. A. M.; HENRIQUE, D. S.; MANCIO, A. B.; PEREIRA, J. C. Avaliação de sistemas de produção de caprinos leiteiros na Região Sudeste do Brasil. Revista Brasileira de Zootecnia, Viçosa, v. 37, n. 2, p. 366-376, 2008. Suplemento.

GRAVERT, H. O. Dairy cattle production. Nova York: Elsevier Science, 1987. 234 p.

HAENLEIN, G. F. W. Goat milk in human nutrition. Small Ruminant Research, Grassy Drive, v. 51, n. 1, p. 155-163, 2004.

HINDRICHSEN， I. K.; WETTSTEIN, H.-R.; MACHMÜLLER, A.; BACH KNUDSEN, K. E.; MADSEN, J.; KREUZER, M. Digestive and metabolic utilization of dairy cows supplemented with concentrates characterized by different carbohydrates. Animal Feed Science and Technology, Amsterdam, v. 126, n. 1, p. 4361, 2006.

HOFFMANN, R.; SERRANO, O.; NEVES, E. M.; THAME, A. C. M.; ENGLER, J. J. C. Administração da empresa agrícola. 7. ed. São Paulo : Pioneira, 1992.

IPHARRAGUERRE, I. R.; IPHARRAGUERRE, R. R.; CLARK, J. H. Performance of lactating dairy cows fed varying amounts of soyhulls as a replacement for corn grain. Journal of Dairy Science, Savoy, v. 85, n. 11, p. 2905-2912, 2002. 
REIS, R. P.; MEDEIROS, A. L.; MONTEIRO, L. A. Custos de produção da atividade leiteira na região sul de Minas Gerais. Organizações Rurais \& Agroindustriais, Lavras, v. 3, n. 2, p. 268-272, 2001.

SCHMIDELY, P.; LLORET-PUJOL, M.; BAS, P.; ROUZEAU, A.; SAUVANT, D. Influence of feed intake and source of dietary carbohydrate on milk yield and composition, nitrogen balance, and plasma constituents of lactating goats. Journal of Dairy Science, Savoy, v. 82, n. 1, p. 747-755, 1999.

SILVA, D. C.; KAZAMA, R.; FAUSTINO, J. O.; ZAMBOM, M. A.; SANTOS, G. T.; BRANCO, A. F. Digestibilidade in vitro e degradabilidade in situ da casca do grão de soja, resíduo de soja e casca de algodão. Acta Scientiarum. Animal Sciences, Maringá, v. 26, n. 4, p. 501-506, 2004.

SILVA, R. R. Agribusiness da caprinocultura de leite no Brasil. Salvador: Bureau, 1998. 74 p.

WOOD, P. D. P. Algebric model of the lactation curve in cattle. Nature, London, v. 206, p. 164-165, 1967.
ZAMBOM, M. A.; ALCALDE, C. R.; HASHIMOTO, J. H.; MACEDO, F. A. F.; PASSIANOTO, G. O.; LIMA, L. S. Parâmetros digestivos, produção e qualidade do leite de cabras Saanen recebendo rações com casca do grão de soja em substituição ao milho. Acta Scientiarum. Animal Sciences, Maringá, v. 29, n. 3, p. 309-316, 2007.

ZAMBOM, M. A.; ALCALDE, C. R.; MARTINS, E. N.; SANTOS, G. T.; MACEDO, F. A. F.; HORST, J. A.; VEIGA, D. R. Curva de lactação e qualidade do leite de cabras Saanen recebendo rações com diferentes relações de volumoso: concentrado. Revista Brasileira de Zootecnia, Viçosa, v. 34, n. 6, p. 2515-2521, 2005 Suplemento.

ZAMBOM, M. A.; SANTOS, G. T.; MODESTO, E. C.; ALCALDE, C. R.; GONÇALVES, G. D.; SILVA, D. C.; SILVA, K. T.; FAUSTINO, J. O. Valor nutricional da casca do grão de soja, farelo de soja, milho moído e farelo de trigo para bovinos. Acta Scientiarum. Animal Sciences, Maringá, v. 23, n. 4, p. 937-943, 2001.

ZERVAS, G.; FEGEROS, K.; KOYTSOTOLIS, K.; GOULAS, C.; MANTZIOS, A. Soy hulls as a replacement for maize in lactating dairy ewe diets with or without dietary fat supplements. Animal Feed Science and Technology, Amsterdam, v. 76, n. 1-2, p. 65-75, 1998. 
